\title{
Assesing the vertical movement of a nematicide in a sandy loam soil and its correspondence using a numerical model (HYDRUS 1D).
}

\author{
D. Márquez, C. Faúndez, E. Aballay, J. Haberland, C. Kremer*
}

University of Chile, School of Agriculture Sciences, Engineering and Soil Department, Av. Santa Rosa 11.315, Santiago, Chile.*Corresponding author: ckremer@uchile.cl

\begin{abstract}
A test under laboratory conditions was performed to typify and model the vertical movement of a nematicide (DiTera) applied at concentrations of 400,700, and $1000 \mathrm{mg} \mathrm{L}^{-1}$ via drip irrigation to a sandy loam class soil confined in tanks of $1 \mathrm{~m}^{3}$. Vacuum extractometers were set up in the tank at different depths to obtain samples of soil solution starting $10 \mathrm{~cm}$ away from the drip emitter. HPLC was used to measure the nematicide concentration in the soil solution. Later HYDRUS 1D was used to model the vertical nematicide concentration considering homogeneous soil. Soil hydraulic parameters were obtained from laboratory experiments whereas the dispersion length was obtained by inverse estimation matching measured and modeled data. Laboratory results showed no significant differences in vertical nematicide (distribution considered a fraction of the initial concentration), having a higher concentration at the surface and decreasing gradually with the depth. The predictive model was able to describe te nematicide behavior of the nematicide according to controlled test, obtaining a $\mathrm{R}^{2}$ of 0.97 , a RMSE of $67.41 \mathrm{mg} \mathrm{L}^{-1}$, a RRMSE of $13.33 \%$ and a Nash of 0.92 . These results confirm the proposed model; however, further studies on this issue are needed, considering different scenarios in laboratory conditions and thus scaling it up to field conditions.
\end{abstract}

Keywords: Pesticide transport, HYDRUS 1D, DiTera, Advection-Dispersion Equation, Numeric Model, Vadose Zone Flux 


\section{Introduction}

The fate of chemical substances in the soil is complex and dynamic, depending on such factors as clay level, soil $\mathrm{pH}$, hydraulic conductivity, structure, and many others (Dec and Dörner, 2014). The importance of knowing the transport and permanence of such chemical compounds in the soil lies in the need to carry out timely applications and predict the behavior and dynamics of chemical substances in areas of interest so as, to optimize product usage and reduce the risk of contamination through deep percolation (Garrido et al., 2015). Fertilizers and pesticides are the most common chemicals applied to soils (Lamberti et al., 1988). Among these, fumigants and synthetic organic nematicides are the most generally applied and these are costly and may potentially pollute the environment (Aballay et al., 2001). In fact, excessive or deficient nematicide applications happen often, and show unpredictable results (Leitao et al., 2014). Thus, this research will be focused in nematicide detection and modeling.

The main constraints for determining the chemical transport in the soil are related to obtaining reliable samples; furthermore, the detection technique must be adapted to the sampling methodology. Thus, detection and quantification techniques are fundamental to determining any chemical product in the soil. Extraction procedures must be adapted to the nature of the chemical compound and existing soil conditions to avoid affecting the soil solution samples (Ramezani et al., 2009). High performance liquid chromatography (HPLC) is one of the techniques used for detecting pesticides and organic compounds; however, the biggest issue for HPLC analysis is the difficulty of obtaining representative samples of the soil solution (Goyal, 2002; Hernández, 1994). Remedial measures should be taken to obtain representative samples of soil solution in different situations depending on; the substrate type, chemical characteristic of the pesticide and the analysis methodology (Regalado et al., 2005). One such methodology is the extraction of soil solution by suction through porous cups, which extracts the retained solution up to water tensions from 70 to $85 \mathrm{cb}$ (Corwin, 2002) without altering the surrounding soil. Modeling the nematicide concentration in the soil profile is a useful tool to understand its behavior in a particular condition. To generate models however, variables of the soil matrix in which the flow occurs, are highly useful to know and understand the factors and processes of the soil system involved in the dynamics of the chemical compounds (Youssef et al., 2005). Numerical models consider the interaction between soil-water and chemical. In this regard, the HYDRUS software make it possible to predict nematicide behavior, solving the Richards and advection-dispersion equations simultaneously by using variables from the soil system to which it is applied (Šimůnek et al., 2016). HYDRUS has been widely used, mainly for modeling water and chemical compounds; for example, leaching of water and nitrogen in sweet sorghum (Ramos et al., 2012), assessment of groundwater pollution risk, modeling ammonia-nitrogen as indicator (Li et al., 2015), assessment of persistence and movement of pesticides in soils (Gupta et al., 2012; Köhne et al., 2006) among others. Yet little work has been done related to nematicide movement (ex: López-Pérez et al., 2006), particularly with biological actives. Therefore, the aims of this study were: (1) to assess the distribution of an organic nematicide, in this case the biological active Myrothecium verrucaria (DiTera, Valent Biosciences Corp.) applied to a sandy loam soil through drip irrigation, and (2) to check the feasibility of a numerical model (HYDRUS 1D) to predict the vertical movement of this active. 


\section{Materials and Methods}

\subsection{Experimental sand}

Four $1 \mathrm{~m}^{3}$ - plastic tanks were filled with a sandy loam soil, which was stabilized to simulate natural conditions. The procedure consisted of incorporating $20 \mathrm{~cm}$ layers of lightly compacted and irrigated soil until reaching a depth of $1 \mathrm{~m}$. After that, each container was treated with continuous wetting-drying processes for 6 months until soil settling. Simultaneously, a $4 \mathrm{~L} \mathrm{~h}^{-1}$ drip emitter was set up at the center of the container's surface, $10 \mathrm{~cm}$ above the soil.

During the container filling, a soil solution extraction system was installed. The extraction system consisted of a set of 4 extractometers installed 10 $\mathrm{cm}$ away from the drip emitter and 20,30, 40 and $50 \mathrm{~cm}$ deep, in each tank (Figure 1). Each tank was considered an experimental unit.

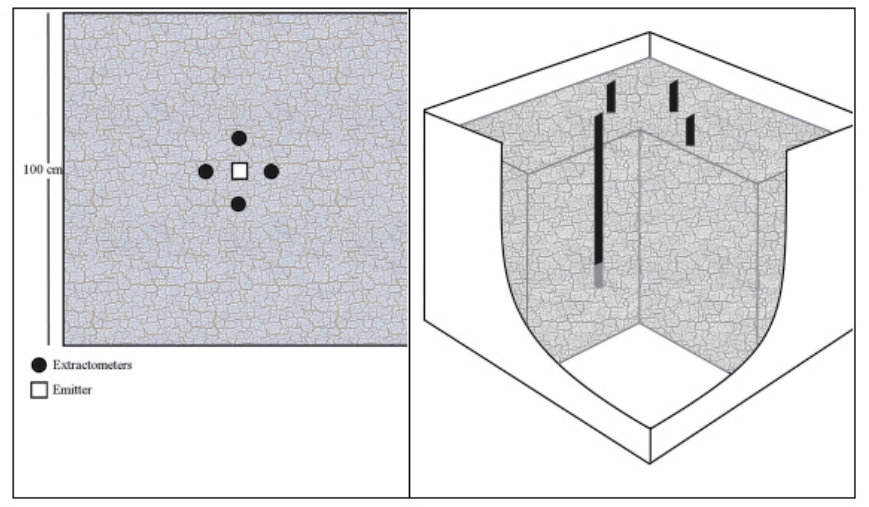

Figure 1. Plane view (left) and longitudinal section (right) of the extractometer setting.

\subsection{Soil features}

The soil was obtained from the Rinconada Lo Vial Soil Series (CIREN, 1996), located in the German Greve Silva experimental field, University of Chile (332' S, 7053' W, Maipú, Santiago, Metropolitan Region). Physical and chemical soil characterizations were performed once it was stabilized in the containers presenting a bulk density of $1.61 \times 10^{3} \mathrm{~kg}$ $\mathrm{m}^{-3}$, a soil water content at field capacity and wilting point of 0.071 and $0.022 \mathrm{~kg} \mathrm{~kg}^{-1}$ respectively, a texture of $74 \%$ of sand , $17 \%$ silk, and $9 \%$ clay, 7.7 $\mathrm{pH} ; 1.8 \times 10^{-1} \mathrm{~S} \mathrm{~m}^{-1}$ of electric conductivity, a cationexchange capacity of $5.3 \mathrm{cmol}^{+} \mathrm{kg}^{-1}$ and $0.08 \%$ of organic matter content.

\subsection{Nematicide}

The nematicide used was DiTera WG, a fermentation product based on a naturally occurring microorganism, Myrothecium verrucaria strain AARC-0255, containing $90 \%$ technical powder with dried fermentation solids and solubles. This fungus has been reported as an active biological agent affecting Meloidogyne hapla, and Globodera rostochiensis, as a potential herbicide, and also has been studied for its electrochemical applications (Dong et al., 2015). Several substances have been characterized from its fermentation, among them bioactive secondary metabolites such as antimicrobial diterpenoids, trichothecene sesquiterpenoids cyclic tetradecapeptides called verrucamides 
(Zou et al., 2011), ), chitinases (Dahiya et al., 2006), bilirubin oxidase (Han et al., 2012) and others. In a previous work by Orellana (2005), seeking an alternative detection method for the presence of DiTera WG using HPLC, a high correlation was found among the peaks on phenolic compounds related to nematicide concentration and nematode mortality. Although the specific chemistry of these peaks was not identified, the analysis through HPLC showed a good performance in a wide range of nematicide concentrations, allowing a calibration equation to be created which relates nematicide concentration in the sample with intensity of absorbance in a specific peak of the chromatography.

\subsection{Description of the extraction system}

A system able to extract and move a soil solution from a specific point in the soil profile to a container on the surface without disturbing the soil around the sampling point was built. This included a set of pipes, valves and a ceramic porous cup connected to a vacuum pump. A microtube inside the system connects the bottom of the ceramic cup with a container on the surface. This allows the soil solution to move from the ceramic cup through the microtube into a plastic container on the surface due to the pressure difference generated.

\subsection{Materials for sample analysis}

For the analysis of the soil extracts, a HPLC analysis was performed in an "Agilent-1200" system with a Nova-Pak column C18 (Waters), $4 \mu \mathrm{m}, 3.9$ x 300 $\mathrm{mm}$, with the oven at $20{ }^{\circ} \mathrm{C}$ attached to a diode array detector (DAD). Solutions of $2 \%$ acetic acid and a mix of acetonitrile, acetic acid and water for the mobile phase $(20 / 2 / 78)$ were used.

\subsection{Calibration curve}

The injection method that made it possible to detect the nematicide in the solution was determined through several calibration tests performed on the HPLC. Once the best injection method was defined, a calibration curve was generated by injecting samples of a known nematicide concentration to link the area generated by the absorbency peak obtained from the HPLC injections to the nematicide concentration (based on Orellana, 2005). The calibration equation obtained was $\mathrm{C}=17.7+2.64 \mathrm{x}$, where $\mathrm{C}$ represents the solution concentration $\left(\mathrm{mg} \mathrm{L}^{-1}\right)$ and $\mathrm{x}$ is the area under the peak (mAU s). The potential disturbance of the sample due to the porous ceramic cups was evaluated by forcing the movement of a solution with a known concentration through the cup and then analyzing its concentration with HPLC. There was no significant difference in the concentration between the mother solutions and those obtained from the porous cup.

\subsection{Adsorption isotherm}

Samples with $2 \mathrm{~g}$ of dry soil and $40 \mathrm{~mL}$ of solution at a known concentration were prepared by adapting the procedure described by Cartón et al., (1997). Samples were shaken for 21 hours, and later an aliquot from the supernatant was extracted for analysis. Adsorption was analyzed for 200,700 and $1000 \mathrm{mg} \mathrm{L}^{-1}$ of nematicide, with no significant differences between the concentrated solution and the supernatants.

\subsection{Protocol of nematicide extraction from the soil}

Three treatments $(\mathrm{T})$ with 4 replicates each were performed: 400 (T1), 700 (T2) and 1000 (T3) $\mathrm{mg} \mathrm{L}^{-1}$. Prior to applying the treatments, the soil contained in the 4 tanks received 4 clean-water irrigations until saturation, and were left to drain. Three days after the 
final irrigation with clean-water, the nematicide was applied through the drip emitter, and the amount of water applied in each application was equivalent to $50 \%$ of available water, estimated from laboratory analysis. The irrigation time was 10 hours. The soil solution was obtained 24 hours after nematicide application; a suction of 90 cbar in a period of 15 minutes was applied to the extractometer system to ensure a representative sample of $10 \mathrm{~cm}$ around the extractioncap (assuming homogeneous extraction), obtaining 50 to $60 \mathrm{~mL}$ of soil solution per extractometer. The 24hour post-irrigation waiting period allowed water to distribute throughout the soil profile and provide data before the chemical degradation of the organic nematicide. To obtain a sample from each depth, a subsample of $50 \mathrm{~mL}$ of soil solution was taken from each depth in each tank. Two sub-samples of $50 \mathrm{~mL}$ from the same coordinate point from 2 different containers were combined and 2 mix-sample repetitions of 100 $\mathrm{mL}$ were obtained for each coordinate point. A 2-mL aliquot was taken from each repetition, filtered at 0.22 $\mu \mathrm{m}$ and injected into the HPLC device to determine the nematicide concentration.

\subsection{Data Analysis}

Once all the data pertaining to nematicide levels in the soil has been obtained, an analysis of variance was carried out on each treatment to determine significant differences between sampling points. The average of the pooled samples from treatments was used to individualize each point.

\subsection{HYDRUS $1 D$ general description}

HYDRUS 1D was parameterized with the soil hydraulic parameters using the van Genuchten retention curve and nematicide information (adsorption isotherm and dispersion length). The dispersion length of the nematicide was obtained by matching the data from the HPLC analysis with the concentrations obtained by the model. The model treats a numerical solution of the one-dimensional Richards equation (1931, Equation 1) to represent the water flux in a porous medium with a variable soil water content, using a finite elements technique.

$$
\frac{\partial \theta(h)}{\partial t}=\frac{\partial}{\partial z}\left(K(h) \frac{\partial h}{\partial z}+K(h)\right)-S(z) \text { Equation } 1
$$

Where $\theta$ is the volumetric water content $\left(\mathrm{cm}^{3} \mathrm{~cm}^{-3}\right), h$ is the water tension on soil (cm), $t$ is the time (h), $K$ is the hydraulic conductivity $\left(\mathrm{cm} \mathrm{h}^{-1}\right), \mathrm{S}$ is the water consumption of plants $\left(\mathrm{cm}^{3} \mathrm{~cm}^{-3} \mathrm{~h}^{-1}\right)$, and $z$ is the vertical spatial coordinate $(\mathrm{cm})$. This experiment did not consider water consumption of plants, therefore $S(z)$ was negligible. The model also include a related module which uses a numerical solution to solve the onedimensional advection-dispersion equation (Equation 2), which represents the nematicide transport from the soil surface through the unsaturated zone.

$$
R \frac{\partial C}{\partial t}=D \frac{\partial^{2} C}{\partial z^{2}}-v \frac{\partial C}{\partial z}-r \text { Equation } 2
$$

Where $C$ is the solute concentration in the liquid phase $\left(\mathrm{mg} \mathrm{L}^{-1}\right), t$ is the time (h), $z$ is the vertical spatial coordinate $(\mathrm{cm}), R$ is the delay factor, which characterizes adsorption processes by the soil ( $R$ was considered equal to 1 since non adsorption was observed from the adsorption isotherm ),$v$ is the flux velocity $\left(\mathrm{cm} \mathrm{h}^{-1}\right)$ in the porous media, $r$ is a term which account for sink and sources of the element $\left(\mathrm{mg} \mathrm{cm} \mathrm{cm}^{-3} \mathrm{~h}^{-1}\right)$, and $D$ is the hydrodynamic dispersion $\left(\mathrm{cm}^{2} \mathrm{~h}^{-1}\right)$. A Galerkin-type linear finite element scheme was used for the spatial distribution and an implicit finite difference scheme was used for the temporal variation of the variables in Equation 1 and 2 . 


\subsection{Space and discretization}

The flow domain and discretization to the simulation model was thought to represent the soil tank condition. Modeling was done for 24 hours at a profile depth of $100 \mathrm{~cm}$, which was divided by means of 101 nodes, 4 of them corresponding to suction extractometers at a depth of 20,30, 40 and $50 \mathrm{~cm}$. Smaller elements were used close to the dripper to guarantee the numerical stability of the model. The time step used was 0.001 day.

\subsection{Initial and boundary conditions}

The initial soil water condition was adjusted to field capacity, considering that the soil was irrigated until saturation and was left to drain for three days before the experiment started, while the initial soil nematicide concentration was measured and set to $0 \mathrm{mg} \mathrm{L}^{-1}$. A time-varying boundary condition was applied to the surface, to which irrigation with the dissolved nematicide was applied for the 10 first hours of the model. A seepage face boundary condition was considered at the bottom of the profile.

\subsection{Model parameterization}

Soil hydraulic properties such as the water retention curve and the saturated hydraulic conductivity, needed to fit the Richards and advection-dispersion equations, were estimated using an analytical model (ROSETTA, Schaap et al., 2001) previously fitted with the physical properties of the soil: texture, bulk density and soil water content at -33 and $-1500 \mathrm{kPa}$. Models of this type are called pedotransfer functions (PTFs) because they translate basic soil data into hydraulic properties. Rosetta is capable of predicting the van Genuchten (1980) (Equation 3) water retention and unsaturated hydraulic conductivity, as well as providing estimates of the saturated hydraulic conductivity.

$$
\theta(h)=\theta r+\frac{\theta s-\theta r}{\left[1+(\alpha h)^{\mathrm{n}}\right]^{1-1 / n}} \text { Equation } 3
$$

Where $\theta(h)$ is the soil water content, as a function of the soil water pressure head $h, \theta r$ and $\theta s$ are residual and saturated water contents, respectively, while $\alpha$ and $n$ are curve shape parameters. This equation can be rewritten to get the relative saturation ( $\mathrm{Se}$; Equation 4):

$$
S e(h)=\frac{\theta(h)-\theta r}{\theta s-\theta r} \quad \text { Equation } 4
$$

This equation is used in conjunction with the poresize distribution model by Mualem (1976) to yield the van Genuchten-Mualem model (van Genuchten, 1980; Equation 5):

$$
K(h)=K s S e^{L}\left(1-\left(1-S e^{1 / \mathrm{n}}\right)^{n}\right)^{2} \quad \text { Equation } 5
$$

Where $K S$ is the soil hydraulic conductivity at the matching point near saturation. The parameter $L(-)$ is an empirical pore tortuosity/connectivity parameter normally assumed to be 0.5 (Mualem, 1976). The dispersion length was selected from manual iteration ranging between 5 and $20 \mathrm{~cm}$ (Radcliffe and Šimůnek, 2010). A value of $10 \mathrm{~cm}$ was chosen within the range which yielded the best adjustment between simulated and observed data.

Dropper precipitation was determined by dividing the dropper flow rate to a circular area with a $30 \mathrm{~cm}$ radius, avoiding water build-ups that would cause numerical swings in the model. This achieved a precipitation of $1.41 \mathrm{cmh}^{-1}$. 


\subsection{Model performance}

The coefficient of determination $\left(\mathrm{R}^{2}\right)$, the root mean square error (RMSE) detailed in Equation 6, the relative root mean square error (RRMSE), which is RMSE divided by the average of the observed data, and the Nash-Sutcliffe model efficiency coefficient (Equation 7) were used to determine model prediction accuracy.

$$
R M S E=\sqrt{\frac{\sum_{i=1}^{N}(O i-P i)^{2}}{N-1}} \text { Equation } 6
$$

Where "Oi" and "Pi" are the observed and predicted values respectively and $\mathrm{N}$ the number of observations.

$$
E=1-\frac{\sum_{t=1}^{T}\left(Q_{o}^{t}-Q_{m}^{t}\right)^{2}}{\sum_{t=1}^{T}\left(Q_{o}^{t}-Q_{o}\right)^{2}} \quad \text { Equation } 7
$$

Where Qo is the average of measured values, $Q_{0}^{t}$ is the value measured in time $t, Q_{m}^{t}$ is the value modeled by time $t$ and $\mathrm{E}$ is the "Nash" coefficient, which varies from minus infinite to 1 .

\section{Results}

\subsection{Characterization of nematicide movement in the soil.}

According to the HPLC analysis of soil solution extractions the vertical distribution of the nematicide for the three treatments is depicted in Table 1. It was found that regardless of the concentration injected, the trend was a higher concentration of nematicide near to the application zone with gradual decreases in depth. On the other hand, the vertical concentration distribution for all treatments exhibited a behavior similar to the wetting front for this soil texture (Bhatnagara and Chauhanb, 2008), where the concentrations tend to move at a higher rate vertically than horizontally, implying a greater nematicide vertical distribution. Figure 2 provides a general idea of the nematicide movement, where the vertical distribution is not completely dependent on the concentration applied and, as McBride (1994) stated, it is closely related to the water flux in the soil. Therefore, it can be inferred that the amount of irrigation applied, its frequency and the initial soil water content play an important role in pesticide transport to lower depths in the soil. Observing the vertical nematicide distribution in each treatment as a fraction of the concentration injected, no significant differences were found at each equivalent depth among the treatments. This fraction distribution of the nematicide movement represented on an isoline map of concentration percentage distribution in depth (Figure 3 ) gives a general idea of its expected distribution under conditions similar to this experiment.

\subsection{Model performance}

The concentration of DiTera was determined through HPLC as described earlier and was also numerically simulated. The output soil parameters later used estimated by ROSETTA were: $\theta r=0.0242 \mathrm{~cm}^{3} \mathrm{~cm}^{-3}, \theta s=$ $0.3417 \mathrm{~cm}^{3} \mathrm{~cm}^{-3}, \alpha=0.0581 \mathrm{~cm}^{-1}, n=1.6103$, and $K s=$ $7.6991 \mathrm{~cm} \mathrm{~h}^{-1}$. Regarding the movement of solutes, diffusion in free water was considered zero and the longitudinal dispersion length obtained by manual iteration matching observed and modeled data was $10 \mathrm{~cm}$.

Figure 4 considers the measured data and modeled concentrations at all depths. The modeled data showed good agreement for the different concentrations, with a low RRMSE near 13\% and a Nash and $\mathrm{R}^{2}$ of 0.922 and 0.967 , respectively. The outcomes obtained through the statistical parameters were within the accepted ranges for chemical product distributions on soil, such as 2,4 D movement (Gupta et al., 2012), nitrates (Al-Darby and Abdel-Nasser, 2006), or salt 
leaching in soil profiles (Zeng et al., 2014), among others. Our result reveals, however, that at lower levels of nematicide the model slightly overestimated the concentration, whereas at higher levels the model slightly underestimated the concentration (Figure 5). Overall, because of the high Nash-Sutcliffe coefficient observed and the low RRMSE, the model behaves very closely to the observed data.

Table 1. Vertical concentration distribution of DiTera nematicide in the soil profile when a concentration of (a) $400 \mathrm{mg} \mathrm{L}^{-1}$, (b) $700 \mathrm{mg} \mathrm{L}^{-1}$, and (c) $1000 \mathrm{mg} \mathrm{L}^{-1}$ were injected.

\begin{tabular}{|c|c|c|c|}
\hline $\begin{array}{l}\text { Injected } \\
\text { Conc. }\end{array}$ & $400 \mathrm{mg} \mathrm{L}^{-1}$ & $700 \mathrm{mg} \mathrm{L}^{-1}$ & $1000 \mathrm{mg} \mathrm{L}^{-1}$ \\
\hline \multicolumn{4}{|l|}{ Point (x/y) } \\
\hline$---\mathrm{cm} / \mathrm{cm}---$ & -- & & \\
\hline $10 /-20$ & $284 \mathrm{a}$ & $561 \mathrm{~b}$ & $857 \mathrm{~b}$ \\
\hline $10 /-30$ & $263 \mathrm{~b}$ & $582 \mathrm{a}$ & $907 a$ \\
\hline $10 /-40$ & $237 \mathrm{c}$ & $483 \mathrm{c}$ & $797 \mathrm{c}$ \\
\hline $10 /-50$ & $183 \mathrm{~d}$ & $335 \mathrm{~d}$ & $579 \mathrm{~d}$ \\
\hline
\end{tabular}

*Average with same letters in the same column show no significant differences, according to the Tukey test ( $p>0.05)$.

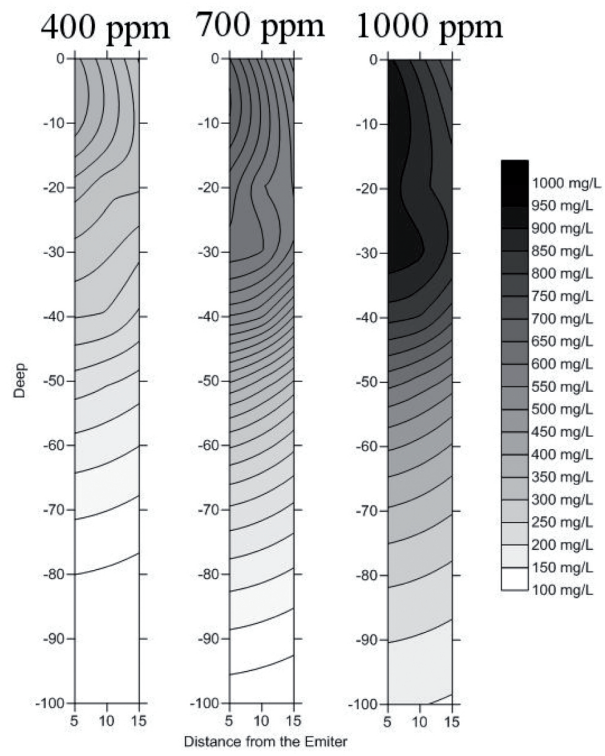

Figure 2. Characterization of the vertical transport of the nematicide, injecting concentrations of 400,700 and $1000 \mathrm{mg} \mathrm{L}^{-1}$ (left to right)

*Characterization using kriging interpolation in the Surfer 10 software, $5 \times 5 \mathrm{~cm}$ grid on a $10 \times 100 \mathrm{~cm}$ frame.

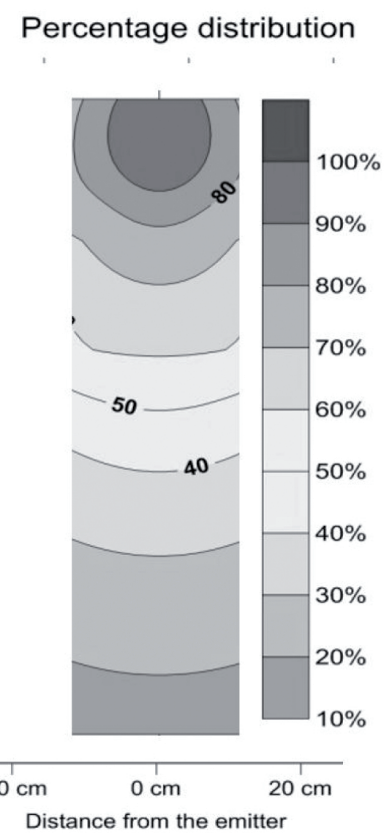

Figure 3. Isolines of percentage distribution of the injected concentration of DiTera nematicide in the soil profile. *Characterization using kriging interpolation in the Surfer 10 software, $5 \times 5 \mathrm{~cm}$ grid on a $30 \times 100 \mathrm{~cm}$ frame. 


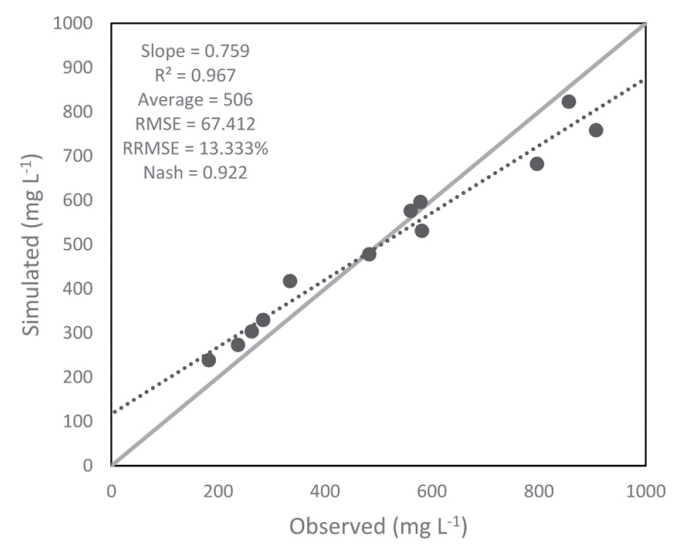

Figure 4. Observed data measured with HPLC on the " $\mathrm{x}$ " axis and data simulated by HYDRUS 1D on the " $y$ " axis. Coefficient of determination $\left(R^{2}\right)$, root mean square error (RMSE), relative root mean square error (RRMSE) and Nash are shown.
Model calibration were performed focusing principally on the vertical distribution of nematicide concentrations due to the 1D structure of the model. The observed concentration distribution was caused mainly by a dispersive flux, taking into account that the soil organic matter content was low $(0.08 \%)$ and adsorption was not detected through the isotherm. An example of the importance of dispersive flux in nematicide distribution is illustrated in Figure 6. This figure shows the soil water content distribution at different depths and times during and after 10 hours of irrigation modeled by HYDRUS 1D. As observed, the soil water content in the entire soil profile at 24 hours was adequately homogeneous, despite the small differences, and it can therefore be inferred that irrigation water is moved into the soil and vertically distributed almost evenly. However, according to Figure 2, the nematicide distribution at 24 hours was not evenly distributed.
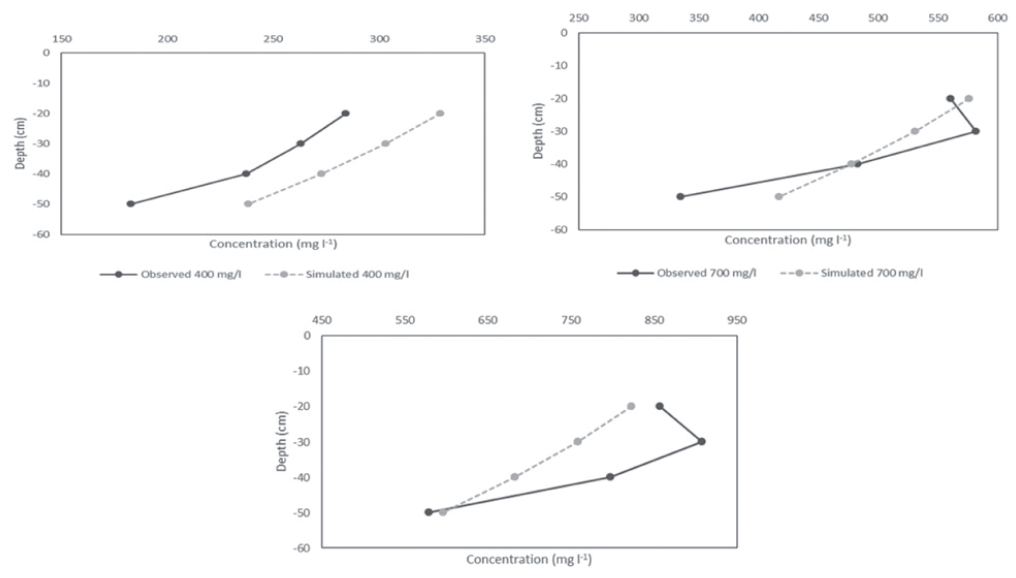

$\rightarrow$ Observed $1000 \mathrm{mg} / 1 \quad-\rightarrow--$ Simulated $1000 \mathrm{mg} / \mathrm{l}$

Figure 5. Nematicide concentration profile in soil depth for the three treatments observed and simulated data. 


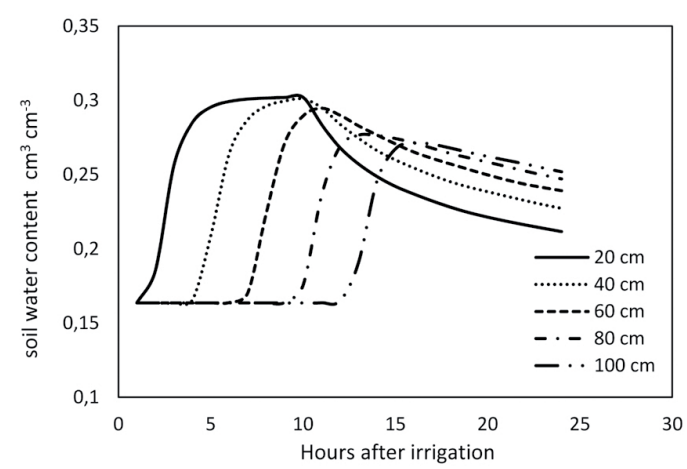

Figure 6. Soil water content distribution at different depths and times during and after 10 hours of irrigation modeled by HYDRUS 1D.

\section{Discussion}

The vertical distribution of the nematicide showed a higher concentration near the application point. Interestingly, no differences were found in the nematicide expressed as a fraction of the concentration applied vertically among treatments. This could mean that in field application it is possible to find an accumulation of this product in the rhizosphere; therefore, it could be interesting to evaluate possible variations in the degradation rate of this pesticide in the rhizosphere (Diez et al., 2015). Even though DiTera transport is closely related to the water movement in the soil and is highly soluble in water, its distribution in the profile was not the same as the water distribution. This finding was unexpected and showed that using the methodology proposed here could be a powerful tool to calibrate mathematical models of agrochemical distributions in soil. Although the result means pointed out an accumulation in the first $20 \mathrm{~cm}$ of soil, the interaction with natural conditions was not evaluated and it is known that pesticides can suffer chemical transformations in a natural environment (Storck et al., 2016); therefore, in future experiments the possible chemical transformation must be assessed under field conditions.

Regarding the model results, it may be said that the transport of DiTera in the soil could be predicted well through the use of the HYDRUS 1D as a modeling system. It is thought that a better performance would likely be obtained if soil water content data were used for the calibration. This consideration could have improved the later results i.e., reduced the overestimation in the lower concentration of nematicide and increased the underestimation in the higher concentrations. Consequently, the amount of water applied as irrigation, its frequency, and the initial soil water content play an important role in the success of the pesticide application. Related to this latter point, it could be interesting to evaluate the DiTera distribution after several irrigations in future studies.

Finally, in this experiment the soil was considered an isotropic medium of hydraulic conductivity, which does not actually conform to reality. While this could have affected the results of the experiment, the high Nash and low RRMSE obtained displayed very good estimations. This could have happened because the initial and boundary conditions were well controlled, and the conditions in the soil were close to saturation which allows for more vertical flux. Additionally, the dispersion length was the only parameter calibrated, meaning that the dispersion value that was ultimately used could have combined and diluted the inefficiencies produced as a result of the other parameters being imposed such that the medium would be considered isotropic. For future surveys in the field, where the boundary and initial conditions usually experience sharp changes, and the quality of the measurements is lower than in laboratory conditions, it may be useful to include the anisotropy coefficient of hydraulic conductivity. This parameter cannot be considered in the 1D model used here; however, in the 2D/3D structure of HYDRUS the anisotropy angle can be included (Šimůnek et al., 2016). 
It should nevertheless be borne in mind that the goal of a model is to be as simple as possible; when complexities are added the model behavior becomes more difficult to understand and to explain (Konikow, 2010). Therefore in the field it is better to begin with this setting up first and only if the model cannot obtain a good Nash coefficient and RRMSE would greater complexity be necessary.

\section{Conclusions}

It was found that in the vertical distribution of the nematicide the higher concentration is near the application point and that distribution is regardless of the concentration applied in each treatment.

The model performed using HYDRUS 1D was able to predict the nematicide movement under this laboratory conditions; thus, it may be said that the transport of DiTera in the soil could be well predicted through the use of the HYDRUS 1D as a modeling system. However, the inclusion of other evaluations in future investigations such as water content measurements over time and the degradation rate of the nematicide, could be useful to improve the outcomes of the model. Finally, it is necessary to conduct more studies considering different scenarios by changing product concentrations, dripper flow and irrigation frequencies under field conditions to validate the use of HYDRUS 1D as a tool for nematicide fate in soil.

\section{References}

Aballay, E., Flores, P., and Insunza, V. 2001. Efecto nematicida de ocho especies vegetales sobre $X i$ phinema americanum sensu lato, en Vitisvinifera L. Var. Cabernet Sauvignon en Chile. Nematropica. 31, 95-102.
Al-Darby, A and Abdel-Nasser, G. 2006. Nitrate leaching through unsaturated soil columns: comparison between numerical and analytical solutions. Journal of Applied Sciences. 6, 735-743.

Bhatnagara, P.R. and Chauhanb, H.S. 2008. Soil water movement under a single surface trickle source. Agricultural Water Management. 95, 799-808.

Cartón, A., Isla, T. and Álvarez-Benedí, J. 1997. Sorption-desorption of imazamethabenz on three spanish soils. Journal of Agricultural and Food Chemistry. 45, 1454-1458.

CIREN CHILE. 1996. Estudio agrológico Región Metropolitana, Centro de Información de Recursos Naturales. Publicación $N^{\circ} 115$. 425p.

Corwin, D.L. 2002. Suction cups. In: Dane, J.H y G.C. Topp (eds.), Methods of Soils Analysis. Part 4. SSSA Book Series: 5, pp: 1261-1266.

Dahiya, N., Tewari, R., and Hoondai, G. 2006. Biotechnological aspects of chitinolytic enzymes: a review. Applied Microbiology and Biotechnology. 71,773-782.

Dong, H., Zhou, X.G., Wang, Y., Xu, J. and Lu, P. 2015. Mirothecium verrucaria strain X-16, a novel parasitic fungus to Meloidogyne hapla. Biological Control. 83, 7-12.

Dec, D. and Dörner, J. 2014. Spatial variability of the hydraulic properties of a drip irrigated andisol under blueberries. Journal of Soil Science and Plant Nutrition. 14(3), 589-601.

Diez, M.C., Schalchli, H., Elgueta, S., Salgado, E., Millahueque, N., Rubilar, O., Tortella, G.R. and Briceño, G. 2015. Rhizosphere effect on pesticide degradation in biobeds under different hydraulic loads. Journal of Soil Science and Plant Nutrition, 15(2), 410-421. 
Garrido, I., Vela, N., Fenoll, J., Navarro, G., PérezLucas, G., and Navarro, S. 2015. Testing of leachability and persistence of sixteen pesticides in three agricultural soils of a semiarid Mediterranean region. Spanish Journal of Agricultural Research, 13(4), 1104.

Goyal, S. (2002). Use of high performance liquid chromatography for soil and plant analysis. Communications in Soil Science and Plant Analysis, 33(15), 2617-2641. DOI: 10.1081/CSS120014468 .

Gupta, M., Grag N.K., Joshi H., and Sharma M.P. 2012. Persistency and mobility of $2,4-\mathrm{D}$ in insaturated soil zone under winter wheat crop in subtropical region of India. Agriculture, Ecosystems and Environment, 146, 60-72.

Han, X., Zhao, M., Lu, L., and Liu Y. 2012. Purification, Characterization and decoloration of bilirubin oxidase from Myrothecium verrucaria. FungalBiology 16, 863-871.

Hernández, F. 1994. Determinaciones analíticas en muestras de la zona no saturada. En Investigación en zona no saturada: aspectos metodológicos y algunos ejemplos. Universitat Jaume I, pp: 29-52.

Köhne, J., Köhne, S. and Šimůnek, J. 2006. Multiprocess herbicide transport in structured soil colums: Experiments and model analysis. Journal of Contaminant Hidrology. 85, 1-32.

Konikow, L. 2010. The secret to Successful SoluteTransport Modeling. Groundwater. 49, 144-159.

Lamberti, F., Roca, F. and Agostinelli, A. 1988. On the identity of Xiphinema americanum in Chile with a key to the Xiphinema species ocurring in Chile. Nematología Mediterránea. 16, 67-68.

Leitao, S., Moreira-Santos, M., Brink, P., Ribeiro, R., Cerejeira, J., and Sousa, J. 2014. Ethoprophos fate on soil-water interface and effects on non-target terrestrial and aquatic biota under Mediterranean crop-based scenarios. Ecotoxicology and Environmental Safety, 103, 36-44.

Li, J., Li, X., Lv, N., Yang, Y., Xi, B., Li, M., Bai, S and Lui, D. 2015. Quantitative assessment of groundwater pollution intensity on typical contaminated sites in China using grey relational analysis and numerical simulation. Environmental earth sciences, 74(5), 3965-3968.

López-Pérez, G.C., Arias, M., López, E., Soto, B.C. and Simal-Gandara, J. 2006. Dynamics of pesticides in potato crops. Journal of Agricultural and Food Chemistry. 54, 1797-1803.

McBride, M., 1994. Environmental chemistry of soils. Oxford University Press, New York, EEUU. $406 \mathrm{p}$.

Mualem, Y. 1976. A new model predicting the hydraulic conductivity of unsaturated porous media. Water Resources Research. 12, 513-522.

Orellana, M.J. 2005. Movimiento en el suelo de extracto de Myrotheciun verrucaria, nematicida biológico, aplicado mediante riego por goteo. Memoria Ingeniera Agrónoma, Universidad de Chile, Chile, 52p.

Radcliffe, D. and Šimůnek, J. 2010. Soil Physics with HYDRUS: Modeling and Applications. Boca Raton, New York: CRC Press, Taylor $\delta$ Francis Group. 373p.

Ramezani, M., Simpson, N., Oliver, D., Kookana, R., Gill, G., Preston, C. 2009. Improved extraction and clean-up of imidazolinone herbicides from soil solutions using different solid-phases sirbents. Journal of Chromatography A. 1216, 5092-5100.

Ramos, T., Šimůnek, J., Goncalves, M., Martins, J., Prazeres, A. and Pereira, L. 2012. Two-dimensional modeling of water and nitrogen fate from sweet sorghum irrigated with fresh and blended saline waters. Agricultural Water Management. $111,87-104$ 
Regalado, C.M., Ritter, A., Rodríguez, R.M. and Socorro, A.R. 2005. Diseño experimental para la extracción de solución del suelo en régimen de insaturación $(\leq 600 \mathrm{kPa})$. Estudios de la Zona No Saturada del Suelo Vol. VI, pp: 95-100.

Schaap, M.G., Leij, F.J. and Van Genuchten, M.Th. 2001. ROSSETA: A computer program for estimating soil hydraulic parameters with hierarchical pedotransfer functions. Journal of Hydrology. 251, 163-176.

Šimůnek, J., van Genuchten, M.T. and Šejna, M. 2016. Recent developments and applications of the HYDRUS computer software packages. Vadose Zone Journal. 15(7), 1-25. doi: 10.2136/ vzj2016.04.0033.

Storck, V., Lucini, L., Mamy, L., Ferrari, F., Papadopoulou, E.S., Nikolaki, S., Karas, P.A., Servien, R., Karpouzas, D.G., Trevisa, M., Benoit, P. and Martin-Laurent, F. 2016. Identification and characterization of tebuconazole transformation products in soil by combining suspect screening and molecular typology. Environmental Pollution. 208, 537-545.
Van Genuchten, M.T. 1980. A closed-form equation for predicting hydraulic conductivity of unsaturated soils. Soil Science Society American Journal. 44, 892-898.

Youssef, M.A., Skaggs, R.W., Chescheir, G.M. and Gilliam, J.W. 2005. The Nitrogen Simulation Model, DRAINMOD-NII. American Society of Agricultural Engineers. 48, 611-626.

Zeng, W, Xu, C., Wei, J. and Huang, J. 2014. Soil salt leaching under different irrigation regimes: HYDRUS 1D modelling and analysis. Journal of Arid Land. 6, 44-58.

Zou, X., Niu, S., Ren, J., Li, E., Liu, X., and Che, Y. 2011. Verrucamides A-D, antibacterial cyclopeptides from Myrothecium verrucaria. Journal of Natural Products. 74, 1111-1116. 